\title{
Nitrogen-doped interconnected carbon nanosheets from pomelo mesocarps for high performance supercapacitors
}

\author{
Hui Peng ${ }^{\mathrm{a}}$, Guofu Ma ${ }^{* a}$, Kanjun Sun ${ }^{\mathrm{b}}$, Zhiguo Zhang ${ }^{\mathrm{a}}$, Qian Yang and Ziqiang Lei ${ }^{{ }^{* a}}$ \\ ${ }^{a}$ Key Laboratory of Eco-Environment-Related Polymer Materials of Ministry of Education, Key Laboratory of Polymer \\ Materials of Gansu Province, College of Chemistry and Chemical Engineering, Northwest Normal University, Lanzhou 730070, \\ China \\ ${ }^{b}$ College of Chemistry and Environmental Science, Lanzhou City University, Lanzhou 730070, China \\ *Corresponding author. E-mail: magf@nwnu.edu.cn; Leizq@nwnu.edu.cn
}

\begin{abstract}
Here, we report a novel type of nitrogen-doped porous interconnected carbon nanosheets derived from an easily gained and green plant-waste (pomelo mesocarps) by simultaneous activation, carbonization and nitrogen-doped processes using $\mathrm{CaCl}_{2}$ as activating agent and urea as nitrogen source. The nitrogen-doped pomelo mesocarps-based nanosheet carbon (N-PMNC) displays an interconnected sheet-like morphology, a high specific surface area $\left(974.6 \mathrm{~m}^{2} \mathrm{~g}^{-1}\right)$, a porous architecture and a high nitrogen doping content $(9.12 \mathrm{wt} \%)$. The N-PMNC based supercapacitor exhibited superior electrochemical performance with high specific capacitance of $245 \mathrm{~F} \mathrm{~g}^{-1}$ at $0.5 \mathrm{~A} \mathrm{~g}^{-1}$ and excellent rate capability (72\% capacitance retention ratio even at $20 \mathrm{~A}$ $\mathrm{g}^{-1}$ ) in $2 \mathrm{~mol} \mathrm{~L}^{-1} \mathrm{KOH}$ electrolyte. Furthermore, N-PMNC based symmetric supercapacitor possesses high specific energy of $14.7 \mathrm{Wh} \mathrm{kg}^{-1}$ at a power density of $90 \mathrm{~W} \mathrm{~kg}^{-1}$ operated in the wide voltage range of $1.8 \mathrm{~V}$ in aqueous neutral $\mathrm{Na}_{2} \mathrm{SO}_{4}$ electrolyte, and shows outstanding cyclic stability.
\end{abstract}


Keywords: Pomelo mesocarps, Carbon nanosheets, Nitrogen-doped, Supercapacitors

\section{Introduction}

As the increasingly fossil energy serious depletion and the emergence of global warming issues, researchers around the world are not only striving to exploit renewable and clean resources (solar, wind, and tidal power), but also development of low-cost, environmentally-friendly and advanced energy storage devices [1-2]. Among the various current energy storage devices, the Li-ion battery has the higher energy density than others. However, its power density is quite low $\left(<3 \mathrm{~kW} \mathrm{~kg}^{-1}\right)$, and it is not suitable for high power demanding devices, such as emergency braking and load leveling systems [3-4]. In comparison, the supercapacitors have a much higher power density (> $10 \mathrm{~kW} \mathrm{~kg}^{-1}$ ), and an acceptable energy density. Additionally, supercapacitors exhibit exceptionally long cycle lifetime [5-6]. The charge storage mechanism of supercapacitors is based on the electrode-electrolyte interfacial electrical double-layer capacitors (EDLCs) with high specific surface area and based on the pseudocapacitance associated with fast surface redox reactions at some metal compounds (metal oxides/hydroxides, metal chalcogenides and so on), conducting polymers, and heteroatom-doped carbon materials [6-8]. Since advanced supercapacitors need to meet the challenges of high performance electroactive materials, including low-cost, abundant available raw materials and enhanced capacitance. One class of materials in whose development and researchers have put intense effort is combining with the electric double layer capacitance and pseudocapacitance performance at a suit [9]. To realize a superior energy density while

maintaining their intrinsic high power density, it is considered to be a promising strategy to develop alternative porous nitrogen-doped carbon-based materials [10]. 
Carbon materials, especially porous biomass-based carbon materials, have attracted intense interests as electrode materials for supercapacitors, because of their low cost, high electrical conductivity and excellent chemical stability $[3,8]$. It is noteworthy that the capacitance value of those carbon materials is highly affected by the specific surface area, pore size and pore distribution $[4,11]$. To overcome this problem, usually, it is necessary to improve the physical/chemical properties of the carbon materials, which can be achieved using different synthesis techniques and activation methods, including their ported physical activation (using steam or $\mathrm{CO}_{2}$ ) or traditional chemical activator activation (using $\mathrm{KOH}, \mathrm{ZnCl}_{2}, \mathrm{H}_{3} \mathrm{PO}_{4}$ and so on) [12-15]. However, these activation methods mainly are to improve the specific surface area and porosity of carbon material, but it seems hard to cause the formation of special architecture (e.g., carbon nanosheets, carbon networks, etc) [1316]. Therefore, it is strongly desirable to develop a simple and effective method to synthesize carbon materials with high surface areas, high graphitization and typical architecture. Besides porosity structure and morphology, heteroatom functional groups (such as nitrogen, oxygen and boron) are built into their surface structures, which have an important direction to enhance the capacitive performance of carbon materials $[9,17]$. The major reason is the increased electric conductivity and surface wettability of carbon electrode materials by heteroatom doping, which can accelerate the charge transport between electrode materials and electrolyte [18]. Therefore, in order to build low-cost and high-performance carbon-based supercapacitors, should be considered carefully the source of raw materials, morphology and hetero-atomic defects of the target materials. Porous nitrogen-doped biomass-based nanosheet carbons seem to meet these requirements and thus are hopeful for supercapacitor applications. 
Herein, we employ one-step activation, carbonization and nitrogen-doped processes by using cheap plantwaste (pomelo mesocarps) as carbon matrix precursor, $\mathrm{CaCl}_{2}$ as activating agent and urea as nitrogen source to obtain the nitrogen-doped pomelo mesocarps-based nanosheet carbon (N-PMNC). The obtained N-PMNC with unique interconnected sheet-like morphology, high specific surface area and high nitrogen doping content would promise high conductivity, fast charge transport and excellent electrochemical capacitance performance.

\section{Experimental}

\subsection{Materials}

Pomelo mesocarps (the pomelo grown in the Guangdong region of China), the calcium chloride $\left(\mathrm{CaCl}_{2}\right)$, urea and potassium hydroxide $(\mathrm{KOH})$ were purchased from Aladdin Ltd. (Shanghai, China). All chemical reagents were in analytical grade and direct used as received.

\subsection{Preparation of nitrogen-doped pomelo mesocarps-based nanosheet carbon (N-PMNC)}

Before the experiments, the obtained pomelo mesocarps was firstly soaked in dilute $\mathrm{HCl}$ solution $(0.1 \mathrm{M})$

for $24 \mathrm{~h}$, and then washed with deionized water and ethanol. After that, the pomelo mesocarps were dried in an air-circulating oven at $60^{\circ} \mathrm{C}$ for $48 \mathrm{~h}$ and then smashed by a disintegrator.

The N-PMNC materials were synthesized as follows: the pretreated pomelo mesocarps $(2.0 \mathrm{~g}), \mathrm{CaCl}_{2}(2.0$ g) and urea $(2.0 \mathrm{~g})$ were added into $30 \mathrm{~mL}$ ethanol solution and followed by evaporation step at $80{ }^{\circ} \mathrm{C}$ under stirring until the formation of viscous solution. And then, the viscous solution was further dried in an aircirculating oven at $80{ }^{\circ} \mathrm{C}$ to form solid precursor mixtures. Finally, the mixtures were activated, carbonized and nitrogen-doped at $800{ }^{\circ} \mathrm{C}$ for $2 \mathrm{~h}$ at a heating rate of $5{ }^{\circ} \mathrm{C} \mathrm{min}^{-1}$ in a slow $\mathrm{N}_{2}$ flow. After cooling to room temperature, the resulting carbon mixture was then thoroughly washed with $2 \mathrm{M} \mathrm{HCl}$ to remove impurities, 
and then the sample was repeatedly washed by distilled water until neutral $\mathrm{pH}$ was reached and dried at $60{ }^{\circ} \mathrm{C}$ in ambient for $24 \mathrm{~h}$. The resulting carbon material is named as N-PMNC.

For comparison purpose, pomelo mesocarps was heated at $800{ }^{\circ} \mathrm{C}$ for $2 \mathrm{~h}$ under $\mathrm{N}_{2}$ flow with a heating rate of $5{ }^{\circ} \mathrm{C} \min ^{-1}$, and the as-obtained carbon is termed as PMC. In addition, the carbonized procedures of the mixtures (1) $\mathrm{CaCl}_{2}(2.0 \mathrm{~g})$ and pomelo mesocarps (2.0 g); (2) urea (2.0 g) and pomelo mesocarps (2.0 g) are the same as the N-PMNC, the obtained samples were denoted as PMNC $\left(\mathrm{CaCl}_{2}\right.$-treated) and N-PMC (ureatreated), respectively.

\subsection{Materials characterizations}

The morphology and microstructure of the as-prepared carbon materials were examined by field emission scanning electron microscopy (FE-SEM, Carl Zeiss-Ultra Plus, Germany) and transmission electron microscopy (TEM, FEI Tecnai G ${ }^{2}$ F20 S-Twin, USA). The crystallographic structure of the materials was determined by X-ray diffraction (XRD, D/Max-2400, Rigaku) equipped with $\mathrm{CuK} \alpha$ radiation $(\mathrm{k}=1.5418 \AA)$. Raman spectra were collected on an inVia Raman spectrometer (Rainie Salt Public Co. Ltd., Britain) with a laser wavelength of $514 \mathrm{~nm}$. The Brunauer-Emmett-Teller (BET) surface area of the samples was analyzed by nitrogen adsorption-desorption in a surface area and porosimetry analyzer (ASAP 2020, Micromeritics, U.S.A.). The elemental (C, $\mathrm{H}$ and $\mathrm{N}$ ) microanalysis was carried out using the Elemental Analyzer Vario EL. Xray photoelectron spectroscopy (XPS) measurement was performed on an Escalab 210 system (Germany) with $\mathrm{Al} \mathrm{K} \alpha$ radiation source.

\subsection{Electrodes fabrication}


For conventional three-electrode system, the glassy carbon electrode (diameter of $5 \mathrm{~mm}$ ) coated with electroactive materials was used as the working electrode; $\mathrm{Hg} / \mathrm{HgO}\left(1 \mathrm{~mol} \mathrm{~L}^{-1} \mathrm{KOH}\right)$ electrode and high purity carbon rod serves as the reference and counter electrode, respectively. The working electrodes were fabricated similar to the reported literature [19]: $4 \mathrm{mg}$ of as-prepared electroactive materials was ultrasonically dispersed in $0.4 \mathrm{~mL}$ of $0.25 \mathrm{wt} \%$ Nafion (DuPont, USA) ethanol solutions. The above homogeneous dispersions of $8 \mu \mathrm{L}$ using a pipet gun was dropped onto the glassy carbon electrode and dried at room temperature naturally. All the three-electrode system is tested in $2 \mathrm{~mol} \mathrm{~L}^{-1} \mathrm{KOH}$ aqueous electrolyte.

For two-electrode symmetric supercapacitor, the working electrode was prepared by mixing the NPMNC, commercial conductive carbon black and binder (polyvinylidene fluoride, PVDF) in a mass ratio of 80:10:10 in N-methyl-2-pyrrolidone (NMP) solution until it forms homogeneous slurry. The slurry was pressed onto nickel foam with a working area of $1.0 \mathrm{~cm}^{2}$ and the electrodes were dried at $120{ }^{\circ} \mathrm{C}$ for $12 \mathrm{~h}$. The total mass loading of the electrode materials was between 2 and $3 \mathrm{mg}$, and two electrodes with identical or very close weights were selected and assembled into the sandwich-type cells device symmetrically using the thin polypropylene film (hydrophilic, thickness of $25 \mu \mathrm{m}$ ) and $0.5 \mathrm{~mol} \mathrm{~L}^{-1} \mathrm{Na}_{2} \mathrm{SO}_{4}$ solutions as the separator and electrolyte, respectively.

\subsection{Electrochemical testing}

The electrochemical properties of the samples were investigated by cyclic voltammetry (CV) and galvanostatic charge/discharge measurements using a CHI 760E electrochemical workstation (Shanghai Chenghua instrument Co., Ltd, China). Electrochemical impedance spectroscopy (EIS) measurements was performed with the Autolab PGSTAT 128N equipped (Eco-chemie, Netherlands) with FRA module, the 
frequency ranging from $0.01 \mathrm{~Hz}$ to $100 \mathrm{k} \mathrm{Hz}$ and an impedance amplitude of $\pm 5 \mathrm{mV}$ at open circuit potential and at different bias potentials. The cycle stability test was performed using LAND CT2001A cycling equipment (Wuhan LAND electronics Co., Ltd., China).

The gravimetric capacitance from galvanostatic charge/discharge was calculated by using the formula of $C_{\mathrm{s}}{ }^{*}=I \Delta t /(m \Delta V)$ for the three electrode system, while, $C_{\mathrm{s}}=4 I \Delta t /(M \Delta V)$ for the two-electrode cells , where $I$ is the constant current (A), $\Delta t$ is the discharge time (s), $m$ is the mass $(\mathrm{g})$ of electrode material $(M$ is the total mass of positive and negative electrodes for two-electrode cells) and $\Delta V$ is the voltage change during the discharge process. Based on a resistance capacitance model, the specific series c apacitance was also calculated from the frequency response analysis, by $C=-1 /\left(2 \pi f Z^{\prime \prime}\right)$, where $f$ is frequency in $\mathrm{Hz}$ and $Z^{\prime \prime}$ is the imaginary part of the impedance, to show the trend of changes in capacitance with frequency [20-21].

The specific energy density $\left(E, \mathrm{Wh} \mathrm{kg}^{-1}\right)$ and power density $\left(P, \mathrm{~W} \mathrm{~kg}^{-1}\right)$ for a symmetric supercapacitor were calculated using equation: $E=1 / 2 C V^{2}$ and $P=E / t$, where $C$ is the specific capacitance of symmetric supercapacitor, $V$ is voltage change during the discharge process and $t$ is the corresponding discharge time.

\section{Results and discussion}

\subsection{Mechanism of the formation of N-PMNC}

The pomelo is subtropical and tropical region cultivated fruit that is produced more than 10 million tons of all over the world every year, and a large number of subsequent plant-waste (pomelo pericarp) don't have an ideal commercial use currently. Especially, the pomelo mesocarp is primarily a combination of lignin and cellulose, which are three-dimensional, highly cross-linked polysaccharose polyphenolic polymer and 
polysaccharose [2]. Such a large interconnected cellulosic fibrils network is an ideal precursor to form interconnected carbon nanosheets. It is well known that $\mathrm{CaCl}_{2}$ has strong adsorption ability, especially has a prominent role in the adsorption of ammonia [22], and it will cause volume expansion in the process of adsorption. Therefore, $\mathrm{CaCl}_{2}$ can play a dual role in the activated carbon precursor process: i) it can be used to fix ammonia which is produced by thermal decomposition of ammonia precursor (e.g., urea, hexamethylene tetramine, etc), and thus lead to high nitrogen content in carbon materials; ii) it can be used as template and expansive agent infiltrated into the carbon precursor, and thus induce formation of developed pore structure in the final product. The schematic illustration for preparation of N-PMNC is shown in Scheme 1. The preparation process mainly consists of two steps: (1) Fabrication of carbon precursor mixtures by mixing the pretreated pomelo mesocarp, $\mathrm{CaCl}_{2}$ and urea in ethanol solution under evaporation process. (2) The activation, carbonization and nitrogen-doped process of the carbon precursor through high temperature pyrolysis under a flowing $\mathrm{N}_{2}$ atmosphere. During the graphitization, the $\mathrm{CaCl}_{2}$ and urea were seeped and incorporated into the cross-linked skeleton of the pomelo mesocarp, which resulted in co-existence of interconnected macropores and developed micro and meso porosity into the structures. Synchronously, nitrogen-containing functional groups can be introduced in carbon skeletons from ammonia gas which is generated through urea pyrolysis. Thus, there is a hope for nitrogen-doped porous carbon with high graphitization, high specific surface area, unique morphology and effective nitrogen doping for the proof-of-concept studies. For comparison purposes, PMC, PMNC and N-PMC are also prepared under different experimental conditions (described in experimental section). 


\subsection{Morphology and structure characterization}

The typical morphology and microstructures of the N-PMNC materials were characterized by use of scanning electron microscopy (SEM) and transmission electron microscopy (TEM), as shown in Figure 1. The N-PMNC exhibits an interconnected sheet-like structure which is connected with the obvious carbon skeleton (Figure 1a). Moreover, the N-PMNC shows soft wrinkles at the edges of the interconnected nanosheets, which arises from the thin walls consisting of a few layers of graphene sheets [23]. In addition, some pores that are also observed in the walls of the sheet-like structure. This unique structure was further confirmed by TEM, as shown in Figure 1b-c. The N-PMNC exhibits ultrathin and folding silk-like edges morphology with highly interconnected carbon skeleton. The high-resolution TEM (HRTEM) image (Figure 1d) also reveals that the NPMNC is composed of mainly disordered amorphous carbon. In addition, ordered graphitic layers of edges and corresponding lattice fringes can be clearly observed and the interplanar distance is measured to be $0.39 \mathrm{~nm}$ (inset of Figure 1d). The highly edges graphitic structure is expected to enhance edelectric conductivity of NPMNC through those orderly graphite conductive edges.

In order to reinforce the discussion concerning the carbonization and activation effect by simultaneous using $\mathrm{CaCl}_{2}$ activation and urea treatment, we further carried out FE-SEM at the same magnification to analyze all the carbon materials under different preparation conditions, as shown in Figure 2. It is found that the PMC (Figure 2a) prepared through carbonization of pure pomelo mesocarp displays large carbon monoliths but with layered large wrinkles, which unique natural layer structure could be conducived to the formation of the nanosheets. The N-PMC prepared only by urea treatment exhibits irregular porous structure in large lumps (Figure 2b), which may be the expansion effect of urea thermal decomposition [24]. Besides, the PMNC 
prepared only by the $\mathrm{CaCl}_{2}$ treatment shows loose and porous networks structure (Figure 2c), but the lamella space between them is still tightly stacked. Distinctively, the N-PMNC has an interconnected sheet-like structure, soft wrinkles edges and developed void space structure (Figure 2d). Therefore, it is reasonable to conclude that the highly interconnected crumpled structure of N-PMNC is caused by the combination of $\mathrm{CaCl}_{2}$ activation and urea expansion. In addition, the interconnected porous nanosheet carbon would provide a unique open-pore system and a short diffusion path for electrolyte ions, which is helpful to improve the electrochemical performance.

To further understand the carbonization process by $\mathrm{CaCl}_{2}$ activation and urea expansion, we have carried out X-ray powder diffraction (XRD) to analyze the changes of hybrid materials after carbonization in different preparation conditions (Figure 3a). Remarkably, the XRD pattern confirmed the main formation of calcium chloride (JCPDS no. 49-1092) and hydrophilite (JCPDS no.24-0223) in after carbonized mixtures of pomelo mesocarp and $\mathrm{CaCl}_{2}$, or carbonized mixtures of pomelo mesocarp, urea and $\mathrm{CaCl}_{2}$ hybrid samples. The results show that the species of $\mathrm{CaCl}_{2}$ did not change in the process of high temperature carbonization. After acid treatment, the final carbide (N-PMNC) displays a typical broad peak at $2 \theta=22.7^{\circ}$ (corresponding interlayer spacing about $0.39 \mathrm{~nm}$ ), which is assigned to the (002) plane of graphitic carbon and the result is in agreement with HRTEM analysis. Figure $3 b$ shows the Raman spectra of all the samples. The D-band (peak at about 1348 $\mathrm{cm}^{-1}$ ) is associated with the disordered structures of carbon, while the G-band (peak at about $1601 \mathrm{~cm}^{-1}$ ) is attributed to graphite in-plane vibrations [25]. Moreover, the relative intensities of these peaks depend on the graphitization degree of the carbon materials, and the ratio of integrated intensity $\left(\mathrm{I}_{\mathrm{D}} / \mathrm{I}_{\mathrm{G}}\right)$ of PMC, PMNC, NPMC and N-PMNC is calculated to be $1.01,0.95,0.96$ and 0.95 , respectively. These results demonstrate that 
carbonized pomelo mesocarps by $\mathrm{CaCl}_{2}$ activation treatment conduce to improve the graphitization degree of carbon and thereby enhance electric conductivity.

The porosity of all samples was analyzed on the basis of nitrogen physisorption measurements. As shown in Figure 3c, all samples show type-IV isotherms (definition by IUPAC) with obvious hysteresis loops in the range of ca. $0.45-0.99 \mathrm{P} / \mathrm{P}_{0}$, suggesting the presence of mesoporous structures [26]. The amount of adsorbed $\mathrm{N}_{2}$ at relative pressures $\mathrm{P} / \mathrm{P}_{0}$ above 0.90 increase remarkably, especially the PMNC and N-PMNC treated by containing $\mathrm{CaCl}_{2}$ as activating agent, demonstrating the presence of large cavities and/or macropores [16]. Besides, sharp increases in volume of N-PMNC at low relative pressure $\left(\mathrm{P} / \mathrm{P}_{0}<0.4\right)$ indicate the presence of a certain amount of micropores. Apparently, the adsorbed volume of N-PMNC is larger than that of other samples. Therefore, it is reasonable to conclude that carbonized pomelo mesocarps by integrate of $\mathrm{CaCl}_{2}$ activation and urea treatment can improve porosity of carbon and form a large pore space. The corresponding pore size distribution curves of all samples are shown in Figure 3d, which are calculated by the Barrett-JoynerHalenda (BJH) method using the adsorption curve. The PMC and N-PMC show low $\mathrm{N}_{2}$ sorption pore volume and have relative low porosity, while the N-PMNC shows noticeable high $\mathrm{N}_{2}$ sorption pore volume and poresize centered in the range of 2-5 nm, suggesting the existence of abundant mesopores.

Elemental analysis, Brunauer-Emmett-Teller (BET) surface area, and pore structure characterization parameters of all as-prepared materials are summarized in Table 1. It is found that the porosity of as-prepared carbon materials is significantly affected by the $\mathrm{CaCl}_{2}$ activating agent and urea. The PMC without any activating agent is used in the synthesis exhibits relative low BET surface area and small pore volume. The pore structure of PMC is mainly composed of the micropores, because its microporous area accounts for the 
vast majority of surface area. However, when only activating agent $\left(\mathrm{CaCl}_{2}\right)$ or only urea is used in the synthesis, both the PMNC and N-PMC possess relative large BET surface areas and pore volumes. To our surprise, the combination of $\mathrm{CaCl}_{2}$ activating agent and urea are used in the synthesis, the N-PMNC have BET surface area as high as $974.6 \mathrm{~m}^{2} \mathrm{~g}^{-1}$, pore volume of $0.69 \mathrm{~cm}^{3} \mathrm{~g}^{-1}$ and the average pore size of $2.9 \mathrm{~nm}$. The specific surface area of N-PMNC is two times greater than the N-PMC and PMNC, even three times greater than PMC. Furthermore, elemental analysis (Table 1) reveal about 9 wt\% N content in both N-PMC and NPMNC which were prepared by urea treatment. These results suggest that combination of $\mathrm{CaCl}_{2}$ activating agent and urea used in the synthesis can increase the BET surface area and nitrogen content of carbon materials.

The surface composition of the N-PMNC sample is further studied by X-ray photoelectron spectroscopy (XPS), corresponding test results as shown in Figure 4a. There are three peaks at around 284.8, 401.1, and $530.8 \mathrm{eV}$ that correspond to the $\mathrm{C} 1 \mathrm{~s}$ peak of $\mathrm{sp}^{2}$ carbon, the $\mathrm{N} 1 \mathrm{~s}$ peak of the doped nitrogen, and the $\mathrm{O} 1 \mathrm{~s}$ spectrum, respectively. Detailed bonding configurations of nitrogen atoms can be obtained from the high resolution $\mathrm{N}$ 1s spectra (Figure 4b). There are four types of N-containing groups can be revealed on the NPMNC, including pyridinic-N (N-6, $398.4 \mathrm{eV})$, pyrrolic-N (N-5, $400.5 \mathrm{eV})$, quaternary-N $(\mathrm{N}-\mathrm{Q}, 401.5 \mathrm{eV})$, and pyridine-N-oxide $(\mathrm{N}-\mathrm{X}, 402.7 \mathrm{eV})$, respectively, indicating that nitrogen atoms are inserted into the nanosheets carbon skeleton in different binding states [16]. Recent studies have shown that the carbons have heteroatoms containing functional groups such as nitrogen and oxygen which can contribute a significant additional pseudocapacitance [27]. Nitrogen atoms inserted into the edges of graphite layers, especially pyridinic-N (N-6) and pyrrolic-N (N-5), are considered to represent the pseudocapacitance behavior [22]. From 
the high resolution $\mathrm{N}$ 1s spectra, one can see that main binding states of N-6 and N-5 types exist in N-PMNC, indicating nitrogen functional groups can effectively provide pseudocapacitance. In addition, the N-PMNC was further characterized by element mapping images of carbon, oxygen and nitrogen to analyze the elemental distribution (Figure 4c). The uniform distribution of blue-green dots (nitrogen) suggests that nitrogen is uniformly doped in N-PMNC skeleton. Thus, it can be assumed that the interconnected porous nanosheet carbon with high nitrogen content can shorten the ion diffusion channels, improve the ion-buffering repositories and provide an additional electric capacity, resulting in excellent performance of electrochemical energy storage.

\subsection{Electrochemical properties}

A three-electrode system was firstly used to evaluate the electrochemical properties of the as-prepared materials by cyclic voltammograms (CVs) and galvanostatic charge/discharge (GCD) techniques. The CVs for the PMC, PMNC, N-PMC and N-PMNC electrodes at a scanning rate of $50 \mathrm{mV} \mathrm{s}^{-1}$ in the potential window of -1.0 to $0 \mathrm{~V}$ versus $\mathrm{Hg} / \mathrm{HgO}$ in $2 \mathrm{M} \mathrm{KOH}$ electrolyte are presented in Figure 5a. The PMC prepared by direct carbonization of pomelo mesocarps exhibits a small irregular triangular curve, indicating low charge response speed because the electrolyte ions cannot diffuse easily and thus lead to an ion sieving effect [28-29]. However, the PMNC and N-PMC are prepared only by $\mathrm{CaCl}_{2}$ treatment or urea treatment, respectively, present rectangular-shaped CVs due to the loose and relative developed porous structure. In contrast, the $\mathrm{CV}$ of the NPMNC shows an ideal rectangular shape, which indicates a superior ion response behavior. Moreover, the NPMNC has a larger CV curve area than that of other electrodes, that is, it has a largest specific capacitance. Besides, the CVs of N-PMNC can retain a stable rectangular-like shape at various scan rate (Figure $5 \mathrm{~b}$ ), 
suggesting the material exhibits an excellent rate capability. The GCD tests of N-PMNC were carried out at various current densities ranging from 0.5 to $20 \mathrm{~A} \mathrm{~g}^{-1}$, as shown in Figure 5c. All the GCD curves are like isosceles triangle and highly symmetrical at various current densities, meaning that such electrode possesses excellent electrochemical reversibility. The specific capacitances of the electrode materials are calculated from GCD curves and the corresponding capacitance value at various current densities for different electrodes are presented in Figure 5d. For the N-PMNC electrode, the specific capacitance is $245 \mathrm{~F} \mathrm{~g}^{-1}$, which value is larger than that of PMC (169 F g $\left.{ }^{-1}\right)$, PMNC (192 F g $\left.{ }^{-1}\right)$ and N-PMC (206 F g $\left.{ }^{-1}\right)$ under same current density $\left(0.5 \mathrm{~A} \mathrm{~g}^{-1}\right)$. It was surprising that the specific capacitance of $\mathrm{N}-\mathrm{PMNC}$ still remains as high as $177 \mathrm{~F} \mathrm{~g}^{-1}$ even at a high current density of $20 \mathrm{~A} \mathrm{~g}^{-1}$ (about $72 \%$ of the capacitance retention). Such electrochemical properties suggest that N-PMNC is the most promising materials for supercapacitor among all as-prepared samples. The above excellent electrochemical properties of N-PMNC are attributed to combination of highly porous and interconnected structure and high nitrogen doping content in carbon nanosheets.

For practical applications, the two-electrode symmetric supercapacitor was also fabricated to further investigate the electrochemical performance of supercapacitor based on N-PMNC electrode. Recent studies show that neutral aqueous electrolyte (such as $\mathrm{Na}_{2} \mathrm{SO}_{4}, \mathrm{Rb}_{2} \mathrm{SO}_{4}$ and $\mathrm{Li}_{2} \mathrm{SO}_{4}$ ) possesses a higher operating voltage than that in acid and alkali electrolytes [30-32]. Therefore, the symmetric supercapacitor based on NPMNC material was assembled in $0.5 \mathrm{M} \mathrm{Na}_{2} \mathrm{SO}_{4}$ electrolyte. In order to confirm the electrochemical stability and operate voltage range of device, the symmetric supercapacitor was firstly measured at different potential range from 1.0 to $2.0 \mathrm{~V}$, as shown in Figure 6a. Surprisingly, the CVs of the symmetric supercapacitor can still keep a perfect rectangular-shaped even the voltage extends to $1.8 \mathrm{~V}$, indicating ideal capacitive behavior and 
outstanding reversibility. But, the voltage can't continue to be expanded to $2.0 \mathrm{~V}$ since the current value in high potential increases sharply, which may be caused by the electrolyte decomposition into hydrogen and/or oxygen evolution [30]. The current voltage range of $1.8 \mathrm{~V}$ is greater than traditional aqueous two-electrode system and it can significantly improve the energy density of supercapacitor according to the equation $E=$ $1 / 2 C V^{2}$. Similarly, GCD curves of symmetric supercapacitor at different voltage ranges from $1.0 \mathrm{~V}$ to $1.8 \mathrm{~V}$ (Figure 6b) also confirm that there is no predominant hydrogen or oxygen evolution behavior and possess ideal electrochemical reversibility. Therefore, the operating voltage of $1.8 \mathrm{~V}$ is chosen for subsequent electrochemical performance tests.

The typical CVs of symmetric supercapacitor at different scan rates from 10 to $200 \mathrm{mV} \mathrm{s}^{-1}$ are displayed in Figure 6c. The CVs shape does not change significantly even at a high scan rate of $200 \mathrm{mV} \mathrm{s}^{-1}$, indicating rapid ions transportation and excellent rate capability. Moreover, GCD curves of symmetric supercapacitor in Figure 6d indicate that the discharging curves are highly symmetrical with their charging counterpart, demonstrating a high electrochemical reversibility. The corresponding electrode specific capacitance (Figure 6e) and Ragone plot (Figure 6f) of the symmetric supercapacitor are calculated from above GCD curves. It is showed that the N-PMNC based symmetric supercapacitor gives a specific capacitance of $112 \mathrm{~F} \mathrm{~g}^{-1}$ at a current density of $0.25 \mathrm{~A} \mathrm{~g}^{-1}$ and the energy density is $14.7 \mathrm{Wh} \mathrm{kg}^{-1}$ at a power density of $90 \mathrm{~W} \mathrm{~kg}^{-1}$. The value of energy density of N-PMNC based symmetric supercapacitor is much higher than those of previously reported carbon-based aqueous symmetric supercapacitor, shuch as nitrogen-doped carbonaceous nanofibers (7.11 Wh $\left.\mathrm{kg}^{-1}\right)$ [33], porous graphene-like nanosheets $\left(9.58 \mathrm{Wh} \mathrm{kg}^{-1}\right)$ [34], hierarchical porous carbon $\left(11.0 \mathrm{Wh} \mathrm{kg}^{-1}\right)$ [35], Nitrogen-doped graphitic carbon nanocages (8.6 $\mathrm{Wh} \mathrm{kg}^{-1}$ ) [36] and mesoporous carbon sheet-like 
framework $\left(9.6 \mathrm{Wh} \mathrm{kg}^{-1}\right)$ [37]. In order to more objective compare the performance of the material, we compared the BET surface area and pore volume of different carbon-based electrode materials as well as their electrochemical properties previously reported in the literature, as listed in Table 2.

EIS analysis is an effective technology to gain a deep insight into the resistive and capacitive behavior of symmetric supercapacitors. Figure 7a show the Nyquist plots of N-PMNC//N-PMNC and PMNC//PMNC symmetric supercapacitor devices recorded at the open circuit potential with the small semicircle in the high frequency region and a vertical line in the low frequency region, indicating that the devices have excellent capacitance performance. The Nyquist plot was fitted by an electric equivalent circuit model shown in the inset of Figure 7a. At high frequencies, the equivalent series resistance $(R s)$ for N-PMNC//N-PMNC device $(2.89 \Omega)$ and PMNC//PMNC device (3.13 $\Omega$ ) are obtained on the intercept at real axis $\left(\mathrm{Z}^{\prime}\right)$, which involves intrinsic resistance of substrate, electrolyte resistance, and contact resistance between the interface of electrode material and current collector interface [41]. The N-PMNC//N-PMNC device also demonstrated a lower charge transfer resistance $(\mathrm{R} c t=2.18 \Omega)$, which value is less than that of PMNC// PMNC device $(\mathrm{R} c t=2.63 \Omega$, as shown in Figure 7a). The result may also be attributed to porous interconnected carbon nanosheets structure and high nitrogen doping content of $\mathrm{N}$-PMNC materials. The slope of the $45^{\circ}$ portion of the curve in mid-frequency is called the Warburg resistance $(\mathrm{Zw})$, which is attributed to the frequency dependence of ion diffusion/transport in the electrolyte to the electrode surface [19]. CPE is the constant phase element. Moreover, we further evaluation the EIS of the N-PMNC//N-PMNC device at different bias potentials from 0 to $1.8 \mathrm{~V}$, as shown in Figure 7b. It can be seen that the Nyquist plots of N-PMNC/N-PMNC device displays a nearly vertical line along the imaginary axis in the low frequency region at the low bias potentials from 0 to $1.0 \mathrm{~V}$, indicating that 
cell voltages affect the charge-discharge responses of a symmetric supercapacitor. However, the deviation from vertical line in the low frequency region with the increase of bias potentials $(1.5 \mathrm{~V}$ and $1.8 \mathrm{~V})$ is attributed to the Faraday-related capacitance behaviour of electrode material [42]. Furthermore, the Rct increase with enlarging bias potentials, which can be attributable to a higher barrier of ion exchange during the charge/discharge process at a larger cell voltage [43]. The specific series capacitances are calculated from the Nyquist plots at ac frequency $f=0.01 \mathrm{~Hz}$ (Figure 7c), which is in a good agreement with the values obtained from the GCD curves of symmetric supercapacitor. The cycling stability of the N-PMNC//N-PMNC device was investigated at a current density of $1 \mathrm{~A} \mathrm{~g}^{-1}$ (Figure 7d). It can be seen that the specific capacitance increases clearly before the initial 2000 cycles, which may be due to the improvement of electrode surface wettability during the initiate charge/discharge process [44]. Subsequently, the specific capacitance decreases slightly and still remains at about $96.5 \%$ of the maximum capacitance after 10,000 cycles, indicating that the N-PMNC electrode material has outstanding electrochemical reversibility and stability in aqueous $\mathrm{Na}_{2} \mathrm{SO}_{4}$ electrolyte.

\section{Conclusions}

In summary, a novel nitrogen-doped pomelo mesocarps-based nanosheet carbon (N-PMNC) derived from a renewable plant-waste (pomelo mesocarps) by simultaneous $\mathrm{CaCl}_{2}$ activation and urea nitrogen-doped processes. The N-PMNC possesses an interconnected sheet-like morphology and a high nitrogen doping content, resulting in high specific capacitance $\left(245 \mathrm{~F} \mathrm{~g}^{-1}\right.$ at $\left.0.5 \mathrm{~A} \mathrm{~g} \mathrm{~g}^{-1}\right)$ and excellent rate capability (retain $177 \mathrm{~F}$ $\mathrm{g}^{-1}$ even at $\left.20 \mathrm{~A} \mathrm{~g}^{-1}\right)$. Furthermore, the as-assembled N-PMNC based symmetric supercapacitor device with a wide operating voltage of $1.8 \mathrm{~V}$ delivers a high specific energy of $14.7 \mathrm{~W} \mathrm{~h} \mathrm{~kg}^{-1}$ and outstanding cyclic 
stability in aqueous $\mathrm{Na}_{2} \mathrm{SO}_{4}$ electrolyte. These findings suggest that the novel N-PMNC material has great potential applications in low-cost energy storage devices and is also expected to be useful as media for hydrogen storage, catalysts support for fuel cell and so on.

\section{Acknowledgements}

The research was financially supported by the China Postdoctoral Science Foundation (2013M540778), the

National Science Foundation of China (NO.21164009, 21174114), the program for Changjiang Scholars and Innovative Research Team in University (IRT15R56), the Science and Technology Program of Gansu Province (NO.1308RJZA295, 1308RJZA265). H. Peng thanks the financial support of this research by the Outstanding Doctoral Dissertation Cultivation Program of Northwest Normal University.

\section{References}

[1] X. Peng, L. Peng, C. Wu, Y. Xie, Two dimensional nanomaterials for flexible supercapacitors. Chem. Soc. Rev. 43 (2014) 3303.

[2] J. Ding, H. Wang, Z. Li, K. Cui, D. Karpuzov, X. Tan, A. Kohandehghan, D. Mitlin, Peanut shell hybrid sodium ion capacitor with extreme energy-power rivals lithium ion capacitors. Energy Environ. Sci. 8 (2015) 941.

[3] H. Jiang, P.S. Lee, C. Li, 3D carbon based nanostructures for advanced supercapacitors. Energy Environ. Sci. 6 (2013) 41.

[4] X. Li, B. Wei, Supercapacitors based on nanostructured carbon. Nano Energy 2 (2013) 159. 
[5] P. Simon, Y. Gogotsi, Materials for electrochemical capacitors. Nature 7 (2008) 845.

[6] F. Béguin, E., Frackowiak, M. Lu (Eds.), Supercapacitors: Materials, Systems, and Applications, Weinheim, 2013.

[7] J. Yan, Q. Wang, T. Wei, Z. Fan, Recent advances in design and fabrication of electrochemical supercapacitors with high energy densities. Adv. Energy Mater. 4 (2014) 1300816.

[8] K. Fic, E. Frackowiak, F. Béguin, Unusual energy enhancement in carbon-based electrochemical capacitors. J. Mater. Chem. 22 (2012) 24213.

[9] C. Yuan, B. Gao, L. Shen, S. Yang, L. Hao, X. Lu, F. Zhang, L. Zhang, X. Zhang, Hierarchically structured carbon-based composites: design, synthesis and their application in electrochemical capacitors. Nanoscale 3 (2011) 529.

[10] X. Wu, L. Jiang, C. Long, Z. Fan, From flour to honeycomb-like carbon foam: carbon makes room for high energy density supercapacitors. Nano Energy 13 (2015) 527.

[11] X. Ning, W. Zhong, S. Li, Y. Wang, W. Yang, High performance nitrogen-doped porous graphene/carbon frameworks for supercapacitors. J. Mater. Chem. A 2 (2014) 8859.

[12] F.C. Wu, R.L. Tseng, C.C. Hu, C.C. Wang, Physical and electrochemical characterization of activated carbons prepared from firwoods for supercapacitors. J. Power Sources 138 (2004) 351.

[13] T. Tooming, T. Thomberg, H. Kurig, A. Jänes, E. Lust, High power density supercapacitors based on the carbon dioxide activated D-glucose derived carbon electrodes and 1-ethyl-3-methylimidazolium tetrafluoroborate ionic liquid. J. Power Sources 280 (2015) 667. 
[14] E. Tee, I. Tallo, H. Kurig, T. Thomberg, A. Jänes1, E. Lust, Huge enhancement of energy storage capacity and power density of supercapacitors based on the carbon dioxide activated microporous SiCCDC. Electrochim. Acta 161 (2015) 364.

[15] H. Wang, H. Yi, C. Zhu, X. Wang, H.J. Fan, Functionalized highly porous graphitic carbon fibers for high-rate supercapacitive electrodes. Nano Energy 13 (2015) 658.

[16] H. Peng, G. Ma, K. Sun, J. Mu, Z. Lei, One-step preparation of ultrathin nitrogen-doped carbon nanosheets with ultrahigh pore volume for high-performance supercapacitors. J. Mater. Chem. A 2 (2014) 17297.

[17] W. Shen, W. Fan, Nitrogen-containing porous carbons: synthesis and application. J. Mater. Chem. A 1 (2013) 999.

[18] H. Peng, G. Ma, K. Sun, J. Mu, Z. Zhang, Z. Lei, Facile Synthesis of poly(p-phenylenediamine)-derived three-dimensional porous nitrogen-doped carbon networks for high performance supercapacitors. J. Phys. Chem. C 118 (2014) 29507.

[19] H. Peng, G. Ma, K. Sun, J. Mu, Z. Zhang, Z. Lei, Formation of carbon nanosheets via simultaneous activation and catalytic carbonization of macroporous anion-exchange resin for supercapacitors application. ACS Appl. Mater. Interfaces 6 (2014) 20795.

[20] M. Arulepp, L. Permann, J. Leis, A. Perkson, K. Rumma, A. Jänes, E. Lust, Influence of the solvent properties on the characteristics of a double layer capacitor. J. Power Sources 133 (2004) 320. 
[21] Y. Zhu, S. Murali, M. D. Stoller, K. J. Ganesh, W. Cai, P. J. Ferreira, A. Pirkle, R. M. Wallace, K. A. Cychosz, M. Thommes, D. Su, E. A. Stach, R. S. Ruoff, Carbon-based supercapacitors produced by activation of graphene. Science 332 (2011) 1537.

[22] M.M. Tokarev, J.V. Veselovskaya, H. Yanagi, Y.I. Aristov, Novel ammonia sorbents "porous matrix modified by active salt" for adsorptive heat transformation: 2. calcium chloride in ACF felt. Appl. Therm. Eng. 30 (2010) 845.

[23] Y. Li, Z. Li, P. Shen, Simultaneous formation of ultrahigh surface area and three-dimensional hierarchical porous grapheme-like networks for fast and highly stable supercapacitors. Adv. Mater. 25 (2013) 2474.

[24] S. Wakeland, R. Martinez, J.K. Grey, C.C. Luhrs, Production of graphene from graphite oxide using urea as expansion-reduction agent. Carbon 48 (2010) 3463.

[25] A.L.M. Reddy, A. Srivastava, S.R. Gowda, H. Gullapalli, M. Dubey, P.M. Ajayan, Synthesis of nitrogendoped graphene films for lithium battery application. ACS Nano 4 (2010) 6337.

[26] P. Su, L. Jiang, J. Zhao, J. Yan, C. Li, Q. Yang, Mesoporous graphitic carbon nanodisks fabricated via catalytic carbonization of coordination polymers. Chem. Commun. 48 (2012) 8769.

[27] D. Hulicova-Jurcakova, M. Seredych, G. Lu, T.J. Bandosz, Combined effect of nitrogen- and oxygencontaining functional groups of microporous activated carbon on its electrochemical performance in supercapacitors. Adv. Funct. Mater. 19 (2009) 438.

[28] G. Salitra, A. Soffer, L. Eliad, Y. Cohen, D. Aurbach, Carbon electrodes for double-layer capacitors I. relations between ion and pore dimensions. J. Electrochem. Soc. 147 (2000) 2486. 
[29] A Jänes, L Permann, M Arulepp, E Lust, Electrochemical characteristics of nanoporous carbide-derived carbon materials in non-aqueous electrolyte solutions. Electrochem. Commun. 6 (2004) 313.

[30] Q. Wang, J. Yan, Y. Wang, T. Wei, M. Zhang, X. Jing, Z. Fan, Three-dimensional flower-like and hierarchical porous carbon materials as high-rate performance electrodes for supercapacitors. Carbon 67 (2014) 119.

[31] A. Jänes, J. Eskusson, L. Mattisen, E. Lust, Electrochemical behaviour of hybrid devices based on $\mathrm{Na}_{2} \mathrm{SO}_{4}$ and $\mathrm{Rb}_{2} \mathrm{SO}_{4}$ neutral aqueous electrolytes and carbon electrodes within wide cell potential region. J. Solid State Electrochem. 19 (2015) 769.

[32] X. Sun, X. Zhang, H. Zhang, D. Zhang, Y. Ma, A comparative study of activated carbon-based symmetric supercapacitors in $\mathrm{Li}_{2} \mathrm{SO}_{4}$ and $\mathrm{KOH}$ aqueous electrolytes. J. Solid State Electrochem. 16 (2012) 2597.

[33] L. Chen, X. Zhang, H. Liang, M. Kong, Q. Guan, P. Chen, Z. Wu, S. Yu, Synthesis of nitrogen-doped porous carbon nanofibers as an efficient electrode material for supercapacitors. ACS Nano 6 (2012) 7092.

[34] L. Sun, C. Tian, M. Li, X. Meng, L. Wang, R. Wang, J. Yin, H. Fu, From coconut shell to porous graphene-like nanosheets for high-power supercapacitors. J. Mater. Chem. A 1 (2013) 6462.

[35] Y. Guo, Z. Shi, M. Chen, C. Wang, Hierarchical porous carbon derived from sulfonated pitch for electrical double layer capacitors. J. Power Sources 252 (2014), 235.

[36] Y. Tan, C. Xu, G. Chen, Z. Liu, M. Ma, Q. Xie, N. Zheng, S. Yao, Synthesis of ultrathin nitrogen-doped graphitic carbon nanocages as advanced electrode materials for supercapacitor. ACS Appl. Mater. Interfaces 5 (2013) 2241. 
[37] Q. Wang, J. Yan, T. Wei, J. Feng, Y. Ren, Z. Fan, M. Zhang, X. Jing, Two-dimensional mesoporous carbon sheet-like framework material for high-rate supercapacitors. Carbon 60 (2013) 481.

[38] C. Huang, A. M. Puziy, T. Sun, O. I. Poddubnaya, F. Suárez-García, J. M. D. Tascón, D. HulicovaJurcakova, Capacitive behaviours of phosphorus-rich carbons derived from lignocelluloses. Electrochim. Acta 137 (2014) 219.

[39] Y. Chang, G. Han, D. Fu, F. Liu, M. Li, Y. Li, Larger-scale fabrication of N-doped graphene-fiber mats used in high-performance energy storage. J. Power Sources 252 (2014) 113.

[40] P. Cheng, S. Gao, P. Zang, X. Yang, Y. Bai, H. Xu, Z. Liu, Z. Lei, Hierarchically porous carbon by activation of shiitake mushroom for capacitive energy storage. Carbon 93 (2015) 315.

[41] M. Stoller, R.S. Ruoff, Best practice methods for determining an electrode material's performance for ultracapacitors. Energy Environ. Sci. 3 (2010) 1294.

[42] E. Frackowiak, K. Metenier, V. Bertagna, F. Beguin, Supercapacitor electrodes from multiwalled carbon nanotubes. Appl. Phys. Lett. 77 (2000) 2421.

[43] T. Wu, Y. Chu, C. Hu, L. J. Hardwick, Criteria appointing the highest acceptable cell voltage of asymmetric supercapacitors. Electrochem. Commun. 27 (2013) 81.

[44] Z. Fan, Y. Liu, J. Yan, G. Ning, Q. Wang, T. Wei, L. Zhi, F. Wei, Template-directed synthesis of pillaredporous carbon nanosheet architectures: high-performance electrode materials for supercapacitors. Adv. Energy Mater. 2 (2012) 419. 


\section{Captions:}

Scheme 1. Schematic of the preparation process of N-PMNC materials

Figure 1. (a) FE-SEM images of the N-PMNC. (b, c) TEM images of the N-PMNC under different magnifications. (d) HRTEM image of the N-PMNC.

Figure 2. FE-SEM images of the (a) PMC, (b) N-PMC, (c) PMNC and (d) N-PMNC.

Figure 3. (a) XRD patterns of hybrid carbonize materials and N-PMNC; (b) Raman spectrums of all asprepared carbon materials; (c) Nitrogen adsorption-desorption isotherms and (d) pore size distribution curves of the PMC, PMNC, N-PMC and N-PMNC.

Table 1. Elemental analysis, BET surface area, and pore structure characterization parameters of all asprepared carbon materials.

Figure 4 (a) X-ray photoelectron spectroscopy (XPS) of N-PMNC; (b) High resolution N 1s spectra of NPMNC; (c) Element mapping images of N-PMNC (selected from the square region).

Figure 5. (a) CVs of different electrodes at a scanning rate of $50 \mathrm{mV} \mathrm{s}^{-1}$ carried out in a three-electrode system; (b) CVs of N-PMNC electrode at various scan rates; (c) GCD curves of N-PMNC electrode at various current densities; (d) Specific capacitances of different electrodes at various current densities.

Figure 6. (a, b) CVs and GCD curves of symmetric supercapacitor with various potential ranges at $50 \mathrm{mV} \mathrm{s}^{-1}$ and $0.5 \mathrm{~A} \mathrm{~g} \mathrm{~g}^{-1}$, respectively; (c) $\mathrm{CV}$ curves of the symmetric supercapacitor at various scan rates; (d) GCD curves of the symmetric supercapacitor at various current densities; (e) Specific capacitance as a function of the current densities; (f) Ragone plots of the symmetric supercapacitor and other previously reported carbonbased aqueous symmetric supercapacitors. 
Figure 7. (a) Nyquist plots of the N-PMNC//N-PMNC and PMNC//PMNC symmetric supercapacitor devices (the inset of the equivalent circuit model). (b) Nyquist plots of the N-PMNC//N-PMNC symmetric supercapacitor device at different bias potentials. (c) Specific series capacitance vs. ac frequency dependencies for the symmetric supercapacitor device based on N-PMNC electrodes. (d) Cycling stability of the NPMNC//N-PMNC symmetric supercapacitor device. 


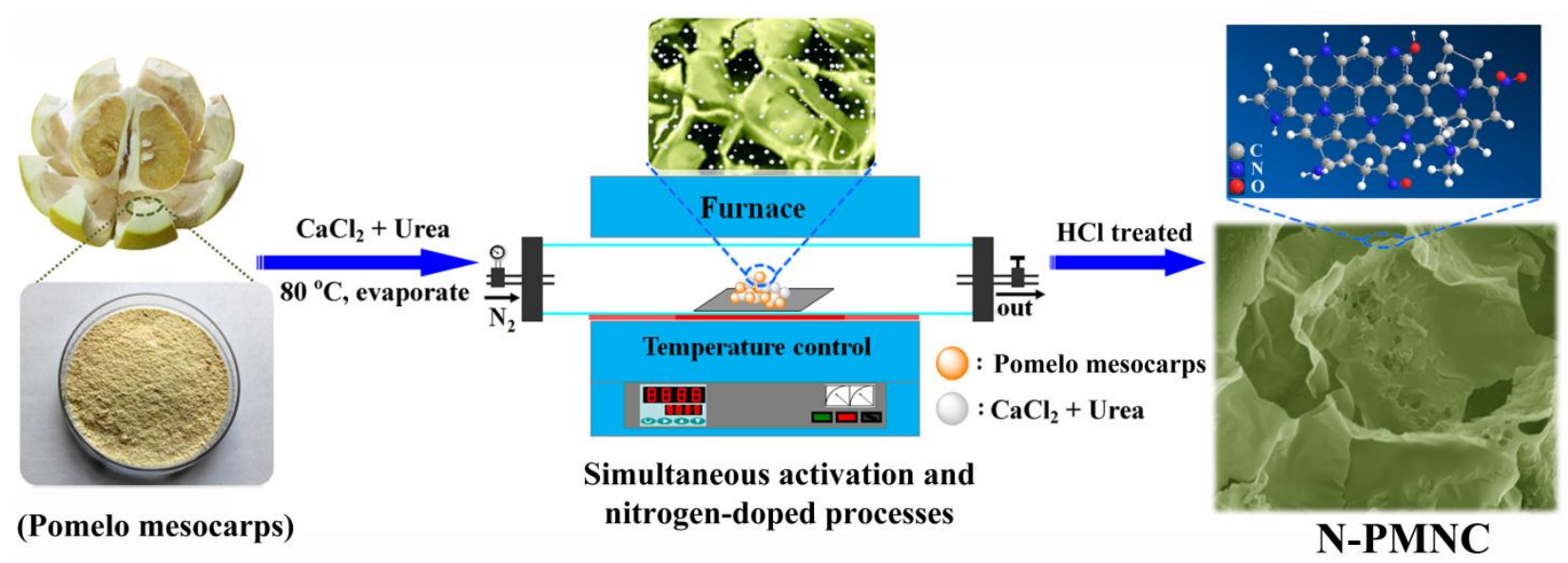

Scheme 1. Schematic of the preparation process of N-PMNC materials 

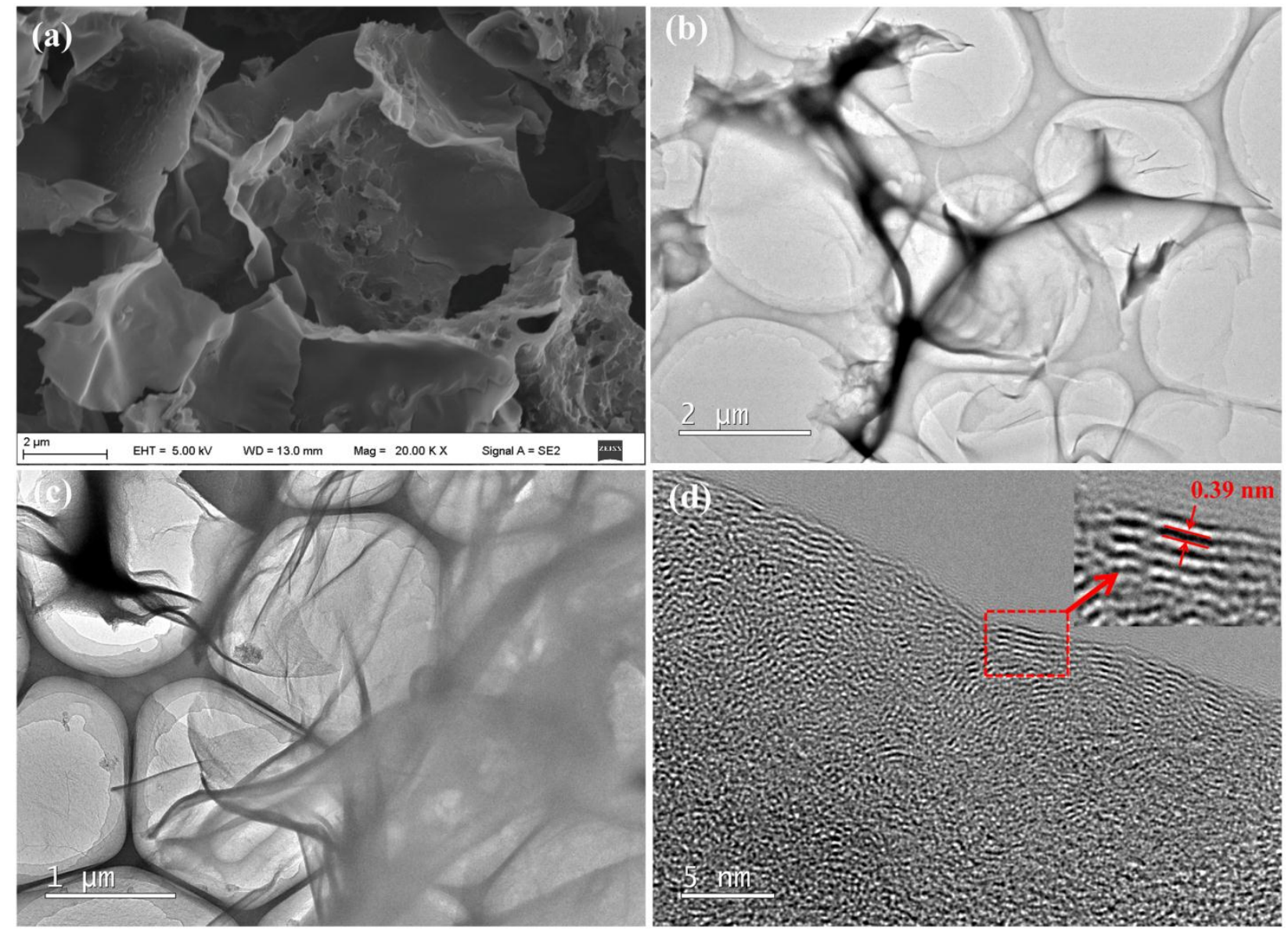

Figure 1. (a) FE-SEM images of the N-PMNC. (b, c) TEM images of the N-PMNC under different magnifications. (d) HRTEM image of the N-PMNC. 


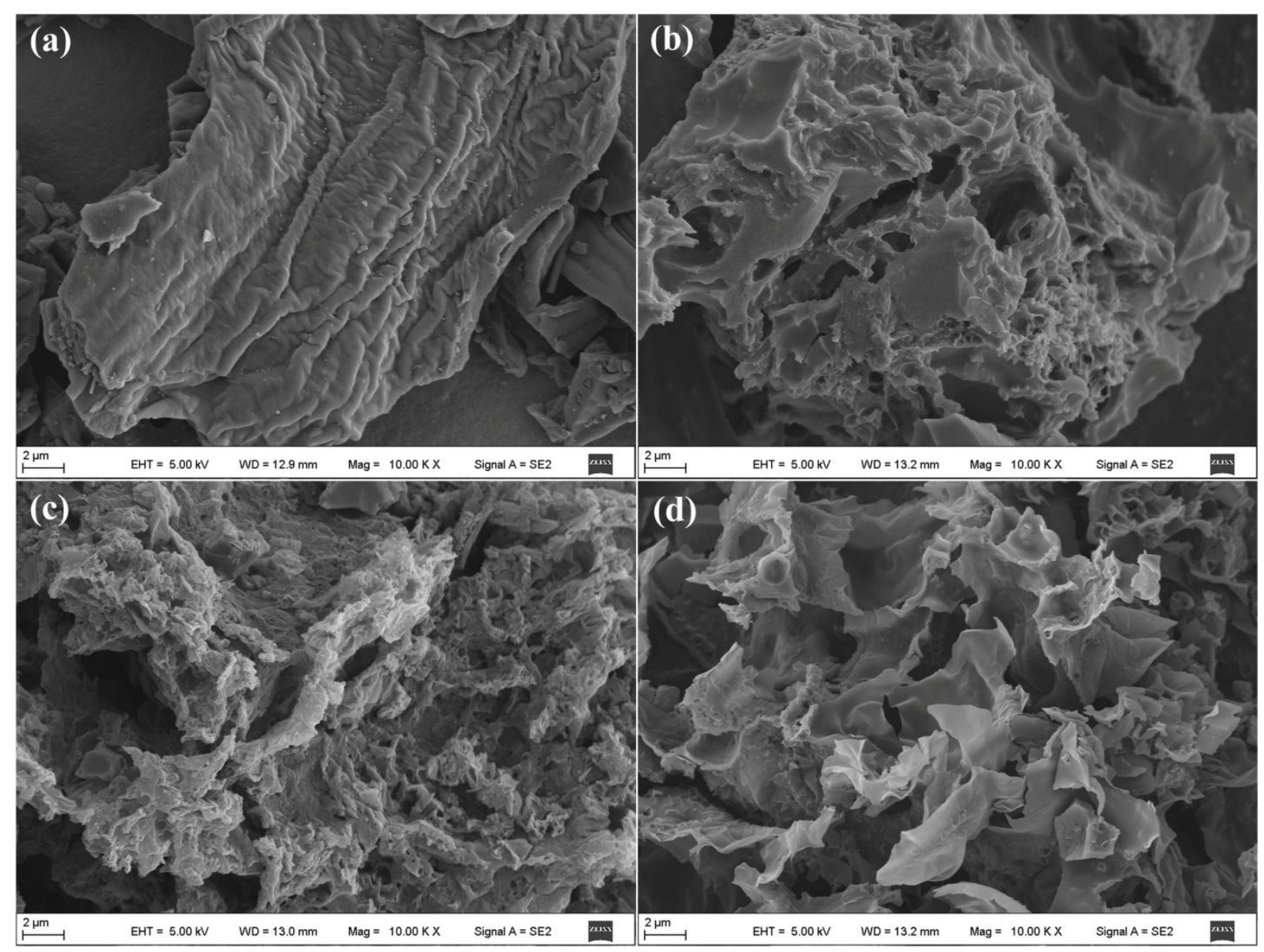

Figure 2. FE-SEM images of the (a) PMC, (b) N-PMC, (c) PMNC and (d) N-PMNC. 
(a)

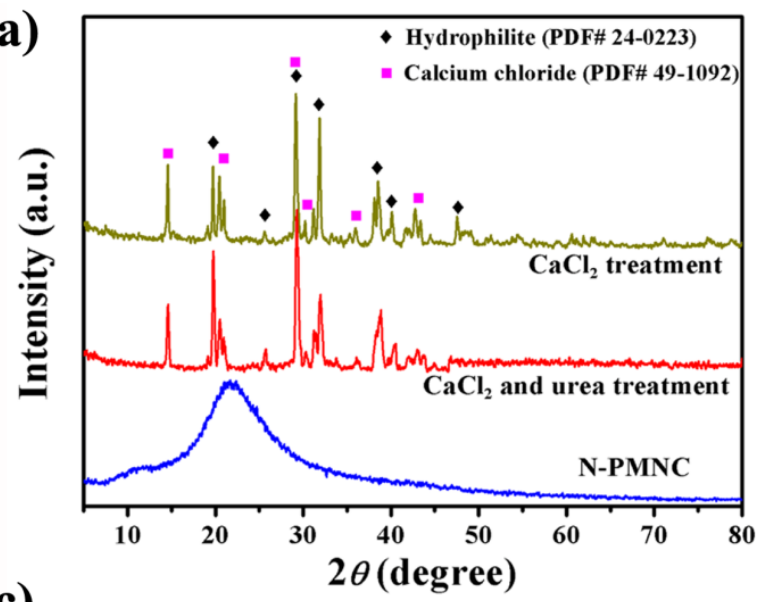

(c)

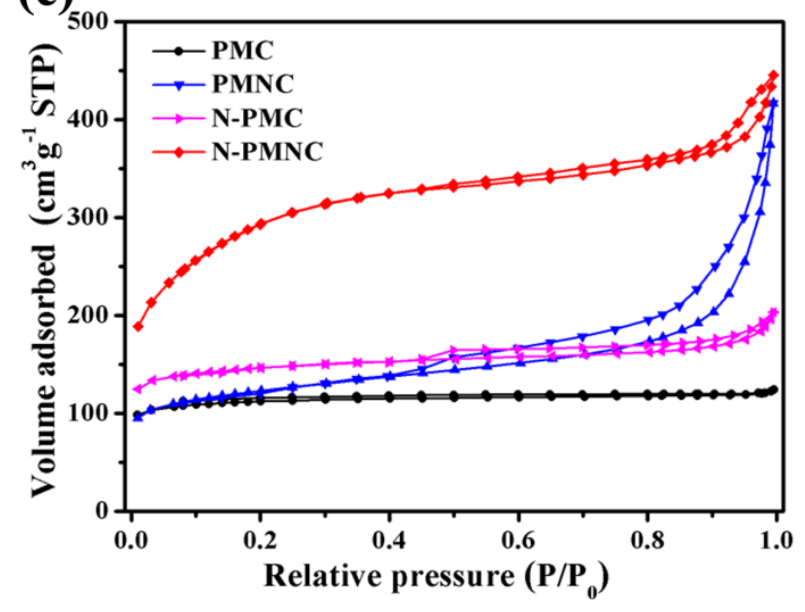

(b)

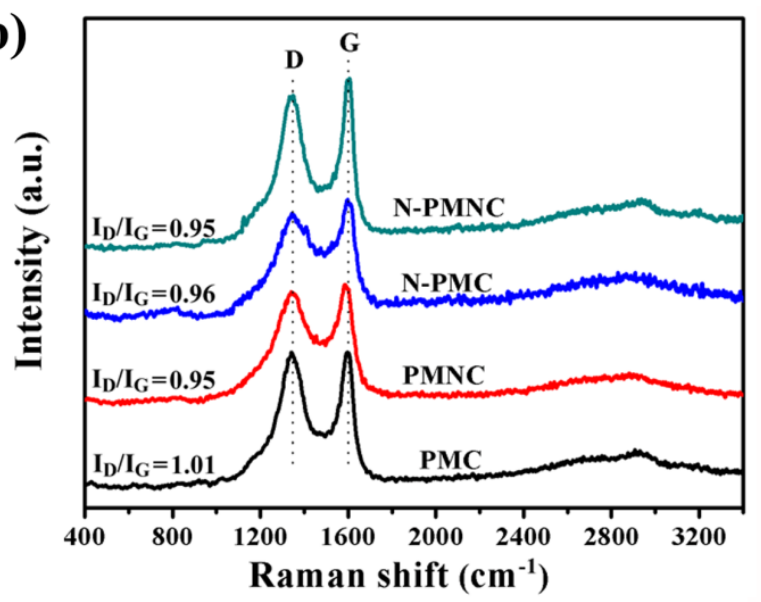

(d)

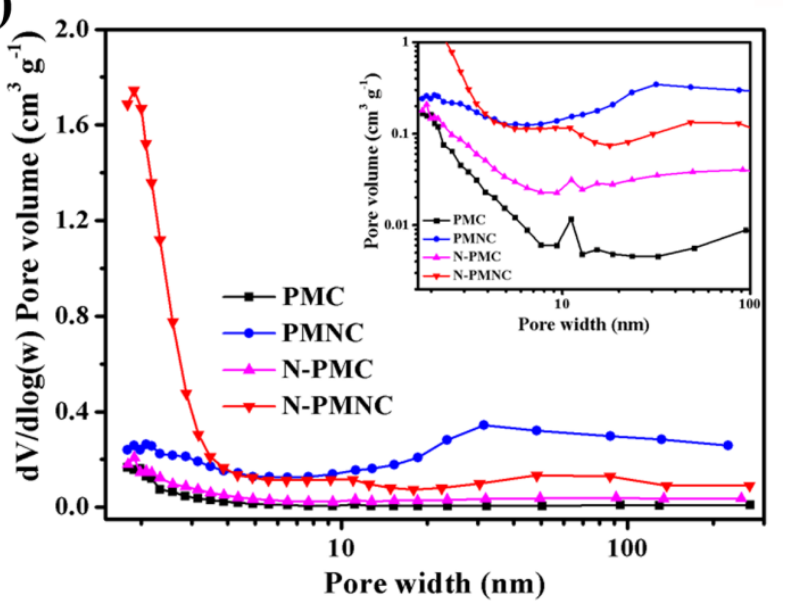

Figure 3. (a) XRD patterns of hybrid carbonize materials and N-PMNC; (b) Raman spectrums of all as-prepared carbon materials; (c) Nitrogen adsorption-desorption isotherms and (d) pore size distribution curves of the PMC, PMNC, N-PMC and N-PMNC. 
Table 1. Elemental analysis, BET surface area, and pore structure characterization parameters of all as-prepared carbon materials.

\begin{tabular}{|c|c|c|c|c|c|c|c|}
\hline \multirow{2}{*}{ Samples } & \multicolumn{3}{|c|}{ Elemental analysis } & \multirow{2}{*}{$\begin{array}{c}\mathbf{S}_{\text {BETT }} \mathbf{a}^{\mathbf{2}} \\
\left(\mathbf{m}^{2} \mathbf{g}^{-1}\right)\end{array}$} & \multirow{2}{*}{$\begin{array}{c}\mathbf{S}_{\mathbf{m i c}}{ }^{\mathbf{b}} \\
\left(\mathbf{m}^{2} \mathbf{g}^{-1}\right)\end{array}$} & \multirow{2}{*}{$\begin{array}{c}V_{\text {total }}{ }^{c} \\
\left(\mathrm{~cm}^{3} \mathbf{g}^{-1}\right)\end{array}$} & \multirow{2}{*}{$\mathbf{D}^{\mathrm{d}}(\mathbf{n m})$} \\
\hline & $\mathrm{C} \%$ & $\mathrm{~N} \%$ & $\mathrm{H} \%$ & & & & \\
\hline PMC & 67.70 & 0 & 1.31 & 304.3 & 269.0 & 0.19 & 2.2 \\
\hline PMNC & 77.41 & 0 & 1.35 & 494.7 & 194.5 & 0.64 & 5.5 \\
\hline N-PMC & 68.58 & 8.99 & 1.39 & 445.8 & 250.9 & 0.24 & 2.7 \\
\hline N-PMNC & 80.95 & 9.12 & 1.37 & 974.6 & 214.7 & 0.69 & 2.9 \\
\hline
\end{tabular}

a) Specific surface area determined according to BET method. b) Micropore surface area from t-plot method.

c) Total pore volume. d) Adsorption average pore diameter. 

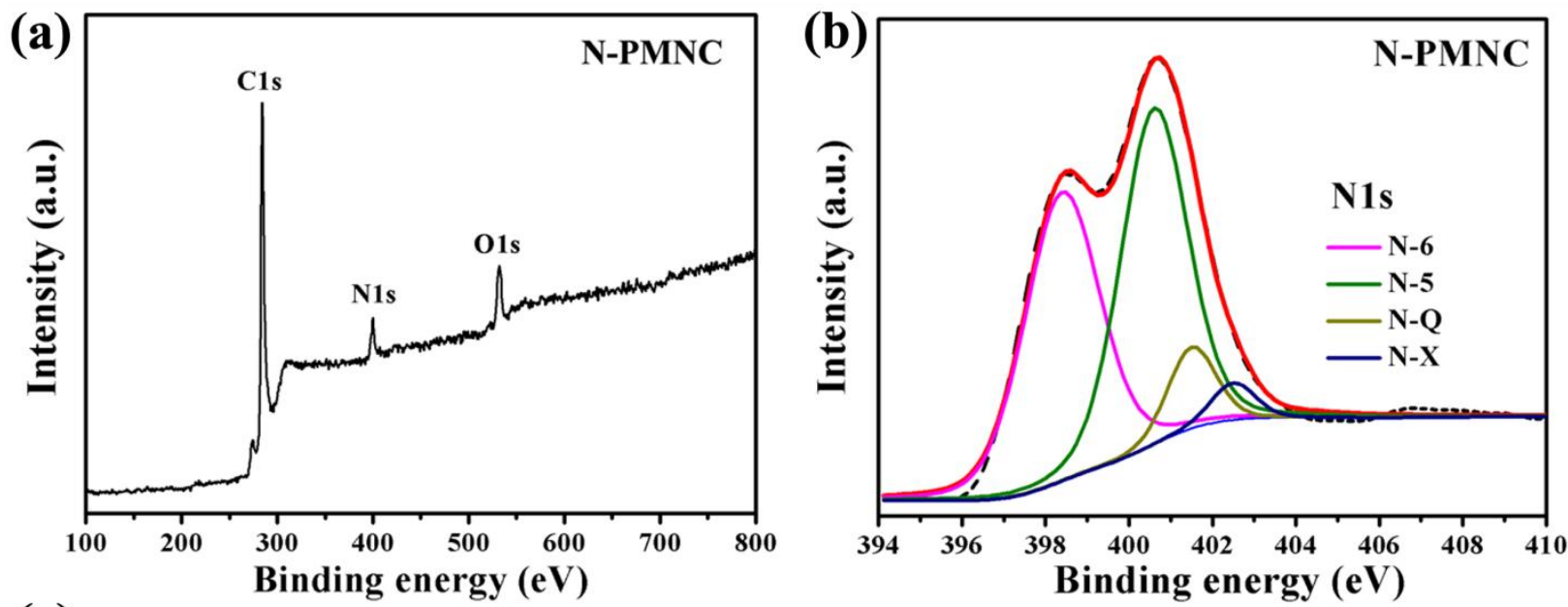

\section{(c)}

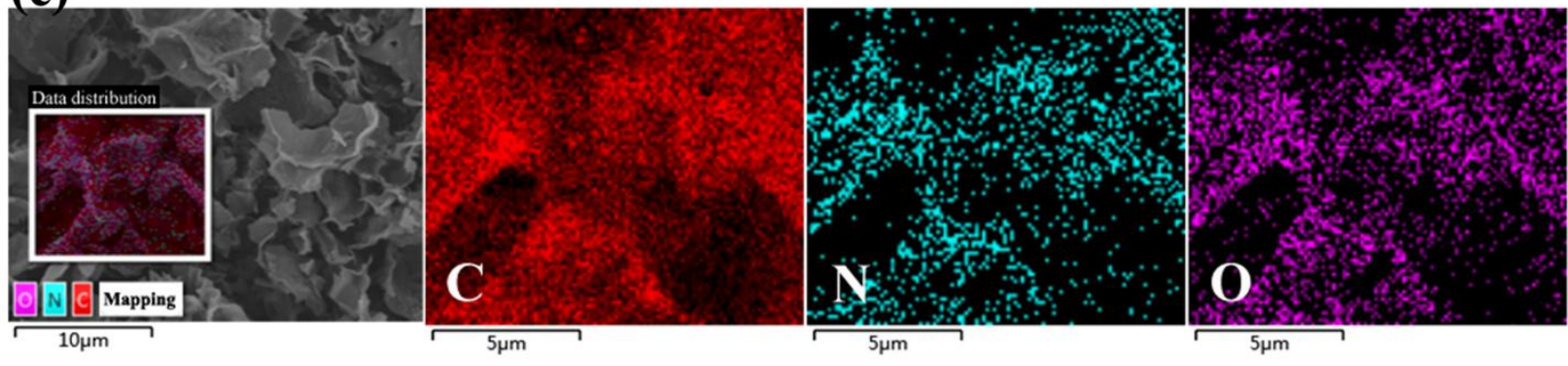

Figure 4 (a) X-ray photoelectron spectroscopy (XPS) of N-PMNC; (b) High resolution N 1s spectra of N-PMNC; (c) Element mapping images of N-PMNC (selected from the square region). 

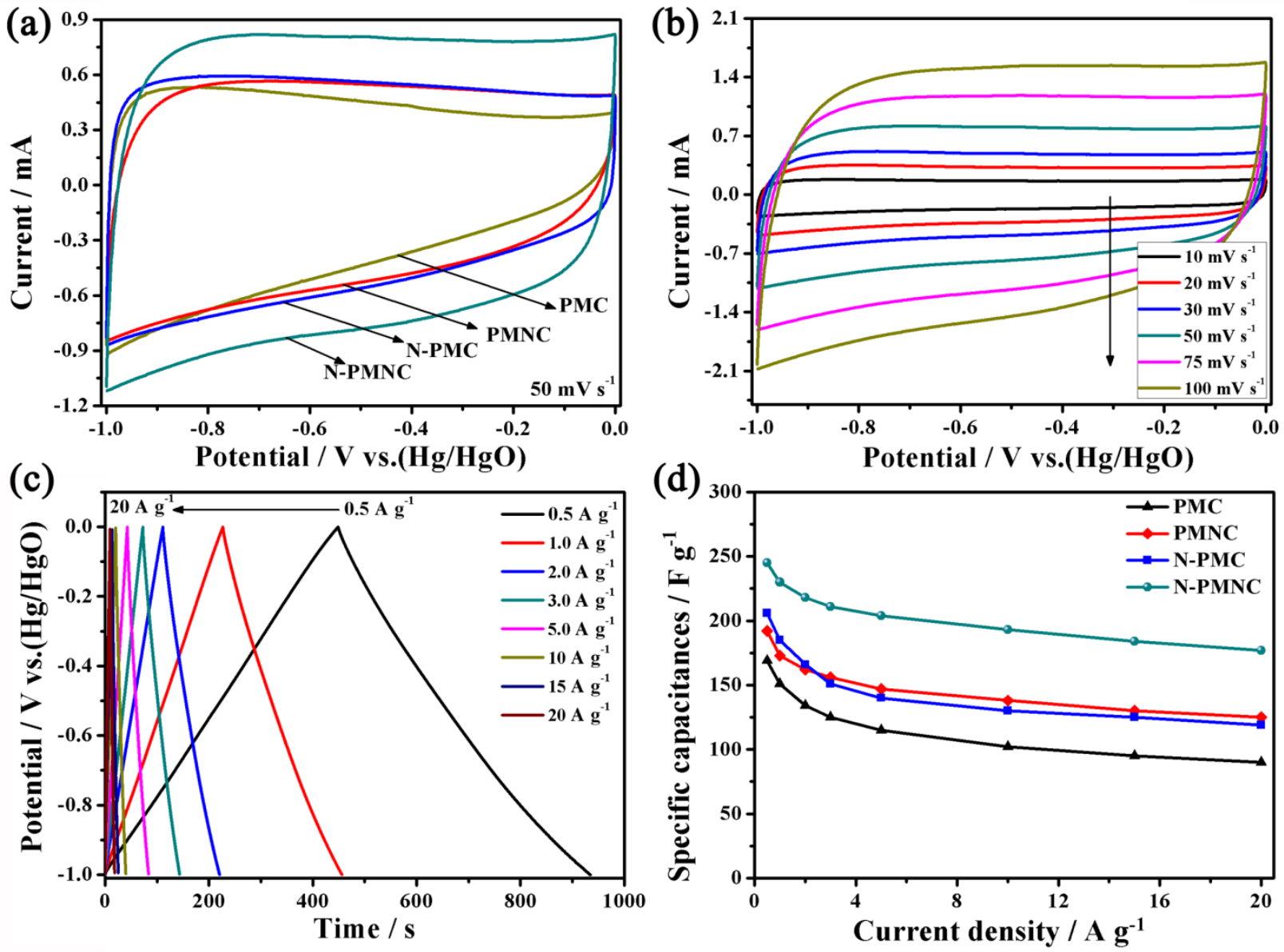

Figure 5. (a) CVs of different electrodes at a scanning rate of $50 \mathrm{mV} \mathrm{s}^{-1}$ carried out in a three-

electrode system; (b) CVs of N-PMNC electrode at various scan rates; (c) GCD curves of N-

PMNC electrode at various current densities; (d) Specific capacitances of different electrodes at various current densities. 

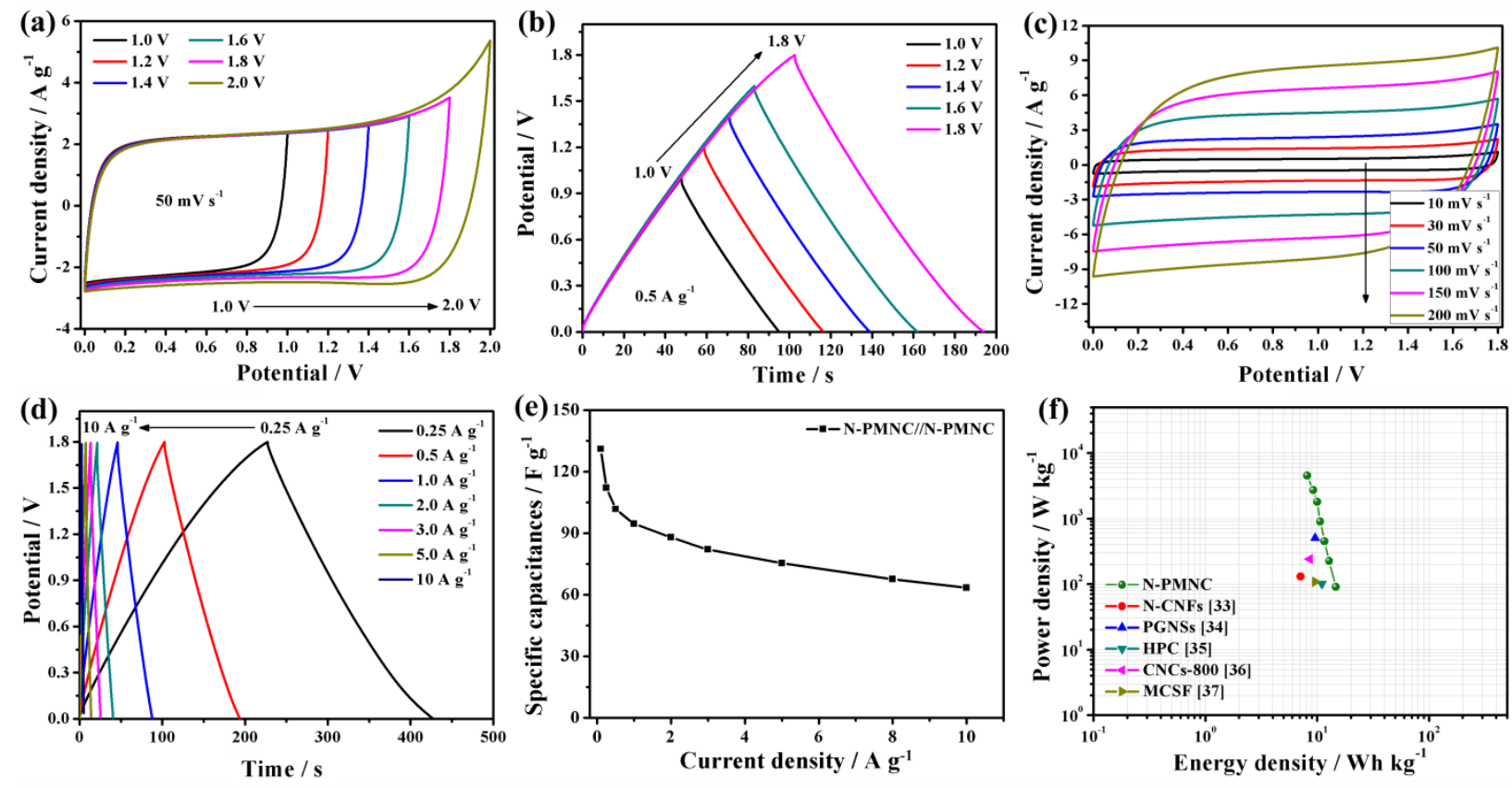

Figure 6. (a, b) CVs and GCD curves of symmetric supercapacitor with various potential ranges at $50 \mathrm{mV} \mathrm{s}^{-1}$ and $0.5 \mathrm{~A} \mathrm{~g}^{-1}$, respectively; (c) $\mathrm{CV}$ curves of the symmetric supercapacitor at various scan rates; (d) GCD curves of the symmetric supercapacitor at various current densities; (e) Specific capacitance as a function of the current densities; (f) Ragone plots of the symmetric supercapacitor and other previously reported carbon-based aqueous symmetric supercapacitors. 
Table 2 Performances comparison of symmetric cells used various carbon materials in the references.

\begin{tabular}{|c|c|c|c|c|c|}
\hline Carbon-based materials & $\begin{array}{l}\text { Specific capacitance } \\
\text { (three electrode) }\end{array}$ & $\begin{array}{c}\text { Cells operation } \\
\text { voltage }(\mathbf{V})\end{array}$ & $\begin{array}{c}E \\
\left(\mathrm{Wh} \mathrm{kg}^{-1}\right)\end{array}$ & $\begin{array}{c}P \\
\left(W \mathbf{k g}^{-1}\right)\end{array}$ & Ref. \\
\hline $\begin{array}{c}\text { Nitrogen-doped pomelo } \\
\text { mesocarps-based nanosheet } \\
\text { carbon (N-PMNC) }\end{array}$ & $245 \mathrm{~F} \mathrm{~g}^{-1}$ at $0.5 \mathrm{~A} \mathrm{~g}^{-1}$ & $\begin{array}{c}1.8 \\
\left(0.5 \mathrm{M} \mathrm{Na}_{2} \mathrm{SO}_{4}\right)\end{array}$ & 14.7 & 90 & $\begin{array}{l}\text { This } \\
\text { work }\end{array}$ \\
\hline $\begin{array}{c}\text { Hierarchical porous carbon } \\
\text { material (FHPC) }\end{array}$ & $294 \mathrm{~F} \mathrm{~g}^{-1}$ at $2 \mathrm{mV} \mathrm{s}^{-1}$ & $\begin{array}{c}1.8 \\
\left(0.5 \mathrm{M} \mathrm{Na}_{2} \mathrm{SO}_{4}\right)\end{array}$ & 15.9 & 317.5 & 30 \\
\hline $\begin{array}{l}\text { Nitrogen-doped carbon nanofiber } \\
\text { (N-CNFs-900) }\end{array}$ & $202 \mathrm{~F} \mathrm{~g}^{-1}$ at $1 \mathrm{~A} \mathrm{~g}^{-1}$ & $\begin{array}{c}1.0 \\
(6 \mathrm{M} \mathrm{KOH})\end{array}$ & 7.11 & $\sim 103$ & 33 \\
\hline $\begin{array}{l}\text { Porous graphene-like nanosheets } \\
\qquad \text { (PGNSs) }\end{array}$ & $268 \mathrm{~F} \mathrm{~g}^{-1}$ at $1 \mathrm{~A} \mathrm{~g}^{-1}$ & $\begin{array}{c}1.0 \\
(6 \mathrm{M} \mathrm{KOH})\end{array}$ & 9.58 & 500 & 34 \\
\hline $\begin{array}{l}\text { Hierarchical porous carbon } \\
\text { (HPC) }\end{array}$ & $212 \mathrm{~F} \mathrm{~g}^{-1}$ at $5 \mathrm{~A} \mathrm{~g}^{-1}$ & $\begin{array}{c}1.6 \\
\left(1 \mathrm{M} \mathrm{Li}_{2} \mathrm{SO}_{4}\right)\end{array}$ & 11 & $\sim 100$ & 35 \\
\hline $\begin{array}{c}\text { Nitrogen-doped graphitic carbon } \\
\text { nanocages (CNCs) }\end{array}$ & $248 \mathrm{~F} \mathrm{~g}^{-1}$ at $1 \mathrm{~A} \mathrm{~g}^{-1}$ & $\begin{array}{c}1.0 \\
(6 \mathrm{M} \mathrm{KOH})\end{array}$ & 8.6 & - & 36 \\
\hline $\begin{array}{l}\text { Mesoporous carbon sheet-like } \\
\text { framework (MCSF) }\end{array}$ & $264 \mathrm{~F} \mathrm{~g}^{-1}$ at $5 \mathrm{mV} \mathrm{s}^{-1}$ & $\begin{array}{c}1.6 \\
\left(1 \mathrm{M} \mathrm{Na}_{2} \mathrm{SO}_{4}\right)\end{array}$ & 9.6 & 108.5 & 37 \\
\hline $\begin{array}{l}\text { Phosphorus and oxygen enriched } \\
\text { carbons (APP900) }\end{array}$ & $166 \mathrm{~F} \mathrm{~g}^{-1}$ at $0.1 \mathrm{~A} \mathrm{~g}^{-1}$ & $\begin{array}{c}1.5 \\
\left(1 \mathrm{M} \mathrm{H}_{2} \mathrm{SO}_{4}\right)\end{array}$ & 6.5 & 3410 & 38 \\
\hline $\begin{array}{l}\mathrm{N} \text {-doped graphene fibers mats } \\
\text { (NG-FMs) }\end{array}$ & $188 \mathrm{~F} \mathrm{~g}^{-1}$ at $5 \mathrm{mV} \mathrm{s}^{-1}$ & $\begin{array}{c}1.0 \\
(25 \% \mathrm{KOH})\end{array}$ & 5.75 & 249.7 & 39 \\
\hline $\begin{array}{l}\text { Shiitake mushroom-based porous } \\
\text { carbon (KPAC-800) }\end{array}$ & $149 \mathrm{~F} \mathrm{~g}^{-1}$ at $0.5 \mathrm{~A} \mathrm{~g}^{-1}$ & $\begin{array}{c}2.5 \\
\left(1 \mathrm{M} \mathrm{TEABF}_{4} / \mathrm{AN}\right)\end{array}$ & 31.7 & 620 & 40 \\
\hline
\end{tabular}



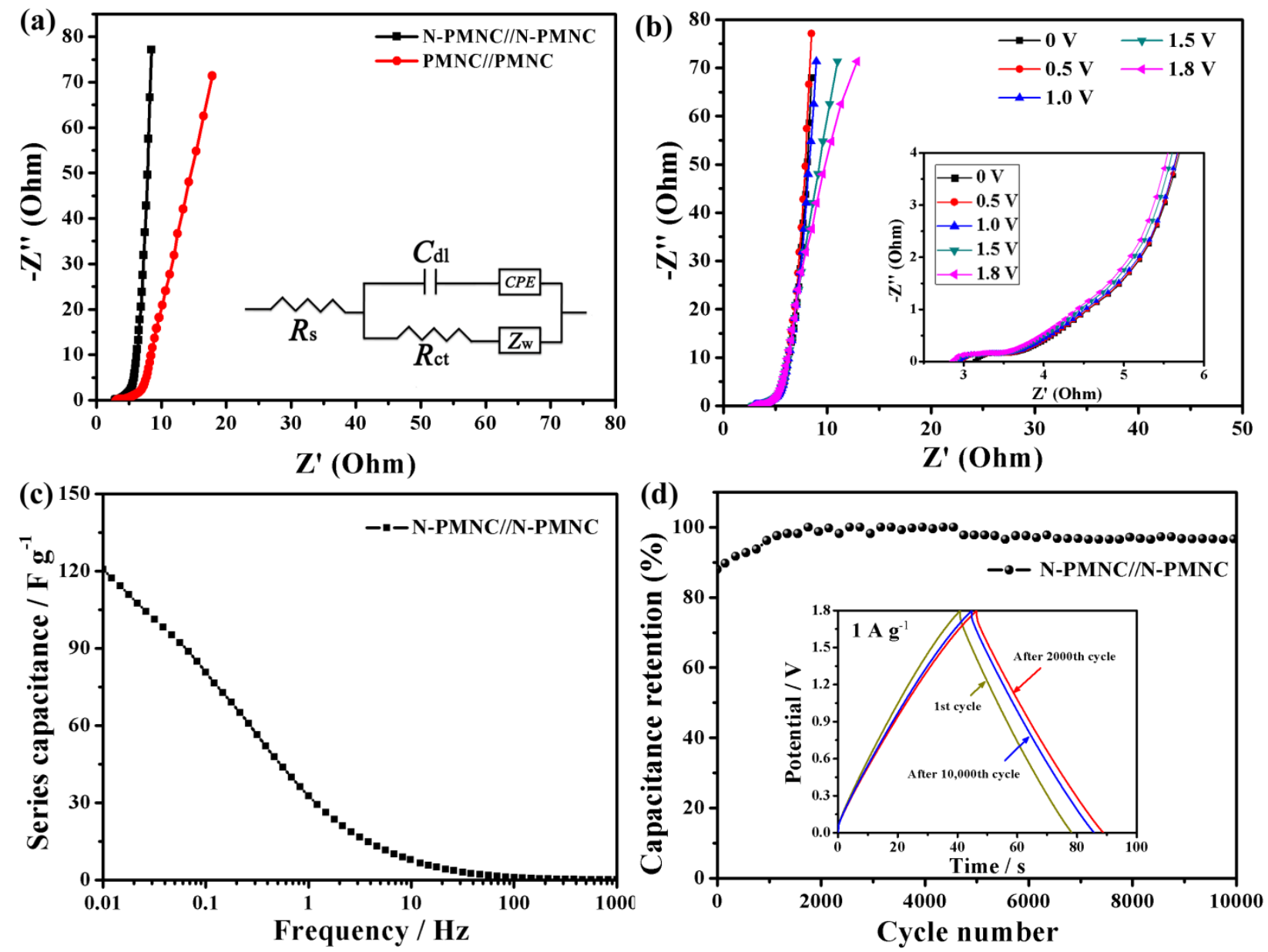

Figure 7. (a) Nyquist plots of the N-PMNC//N-PMNC and PMNC//PMNC symmetric supercapacitor devices (the inset of the equivalent circuit model). (b) Nyquist plots of the NPMNC//N-PMNC symmetric supercapacitor device at different bias potentials. (c) Specific series capacitance vs. ac frequency dependencies for the symmetric supercapacitor device based on N-PMNC electrodes. (d) Cycling stability of the N-PMNC//N-PMNC symmetric supercapacitor device. 